\title{
Hourly and monthly variations in the surface activity patterns of Hemilepistus reaumurii in arid environments of Tunisia
}

\author{
Anas AYARI*, Moez TOUIHRI, Chedlia GHEMARI, Karima NASRI-AMMAR \\ Research Unit of Bio-Ecology and Evolutive Systematics, Faculty of Sciences of Tunis, University of Tunis El Manar, Tunis \\ 2092, Tunisia
}

\begin{abstract}
Life in desert ecosystems drives animals to adapt their surface locomotor activity according to environmental conditions. In this study, the hourly and monthly variations in the surface activity patterns of the terrestrial crustacean Hemilepistus reaumurii were investigated. The surface activity of $H$. reaumurii at the population scale was observed by collecting the hourly active individuals from the sunrise to the sunset of the studied day in each month of 2013 in the Bchachma locality, Tunisia. The collected active individuals were put in perspex boxes (on which we labeled the hourly time interval in which the individuals were collected) in the field and then transported to the laboratory for analysis. Individuals were counted, sexed, and measured in the laboratory. Despite desert conditions in the studied site, $H$. reaumurii was characterized by a diurnal surface activity, showing a bimodal pattern during the warm months (i.e., May to October). However, it exhibited a unimodal surface activity pattern in the cold months (i.e., February, March, and November). The surface activity was significantly correlated with sunrise and sunset. Moreover, a significant quadratic effect of temperature on the surface activity of $H$. reaumurii was observed. Furthermore, the study showed that the most important surface activity was recorded in March. The daily exploitation of the temporal niches was significantly different as a function of months. The body size of males was larger than that of females, and the body size of active individuals changed with months. All these behavioural changes in the surface activity represent an adaptive strategy of life in the arid environment.
\end{abstract}

Keywords: diurnal activity; variation pattern; aboveground activity; desert isopod; temporal niche; Hemilepistus reaumurii; Tunisia

Citation: Anas AYARI, Moez TOUIHRI, Chedlia GHEMARI, Karima NASRI-AMMAR. 2018. Hourly and monthly variations in the surface activity patterns of Hemilepistus reaumurii in arid environments of Tunisia. Journal of Arid Land, 10(3): 470-481. https://doi.org/10.1007/s40333-018-0058-2

\section{Introduction}

The extreme climatic conditions in hot deserts require special adaptations of the inhabitants, especially arthropods (Cloudsley-Thompson, 2001), to tolerate environmental conditions. In tenebrionid beetles, the size, convexity, the presence or absence of a suture on the elytra, colouring and resistance to desiccation and high temperatures represent some of many adaptations that are found in these species (Parmenter et al., 1989). Adaptation also occurs at the behavioural

\footnotetext{
*Corresponding author: Anas AYARI (E-mail: ayari.anas88@gmail.com)

Received 2017-06-29; revised 2018-01-05; accepted 2018-02-03

(C) Xinjiang Institute of Ecology and Geography, Chinese Academy of Sciences, Science Press and Springer-Verlag GmbH Germany, part of Springer Nature 2018
} 
level (Linsenmair, 2007). Many tenebrionid beetles change their activity and zonation to adapt climatic conditions, on a seasonal and daily basis (Chelazzi and Colombini, 1989; Cloudsley-Thompson, 1990).

Locomotor activity patterns of desert animals may be affected by many abiotic factors (e.g., climatic conditions, habitat structure, and quality). The most important strategy of desert animals consists of living in burrows where the air humidity is high and the temperature is moderate (Cloudsley-Thompson, 2001). They limit their aboveground (surface) activity at specific periods of the year and/or at specific periods of the day.

Overall, arthropods are able to avoid the very high temperature and therefore escape the heat by staying in burrows and may have nocturnal activity (Bohli et al., 2006; Bohli-Abderrazak et al., 2012; Jelassi et al., 2013; Ayari et al., 2015, 2017). In fact, temperature appears to be an important determinant of temporal activity patterns for arthropods. Unlike terrestrial isopods, the burrowing isopod Hemilepistus reaumurii (Crustacea), which is commonly distributed in the arid regions of North Africa, Middle East and Central Asia, exhibits a daily activity pattern (Nasri-Ammar and Morgan, 2005; Nasri-Ammar et al., 2016; Ayari et al., 2017). To avoid extreme heat and dryness, $H$. reaumurii individuals must spend most of the time with their brood in a self-dug burrow.

Despite the importance of locomotor behaviour as a survival strategy of this species, few studies have been interested in this aspect. Thus, our study aims to explore the response of $H$. reaumurii population to severe arid climatic conditions (e.g., high temperature and dryness). More specifically, we examine how this isopod species adapts its surface activity to a specific period of a day to survive in the arid environments.

We suppose that $H$. reaumurii would reduce its surface locomotor activity during the warmest months while increase its daily period of surface activity during the months with suitable temperatures. Our second hypothesis supposes that the temporal niche for males and females of $H$. reaumurii is different. More precisely, males would be more active during the dispersal period whereas females would be more active during the period following the reproduction. Furthermore, males and females would restrict their locomotor activity to specific periods of the day to avoid critical temperatures. Our third hypothesis supposes that the body size of active $H$. reaumurii individuals would change with months.

\section{Materials and methods}

\subsection{Study site}

This study was conducted in the Bchachma locality $\left(35^{\circ} 49^{\prime} \mathrm{N}, 10^{\circ} 10^{\prime} \mathrm{E} ; 23 \mathrm{~m}\right.$ a.s.l.) situated near Kairouan, Tunisia. The study site is situated in the marginal area of a salt lake covered by small dunes, called hillocks (Fig. 1). It is characterized by an arid climate. Temperatures are usually mild in winter months $\left(6^{\circ} \mathrm{C}-17^{\circ} \mathrm{C}\right)$ and high in summer months $\left(25^{\circ} \mathrm{C}-42^{\circ} \mathrm{C}\right)$. The average annual precipitation is about $26 \mathrm{~mm}$ (ranging from 6.7 to $49.2 \mathrm{~mm}$ ) and the driest months are July and August. Vegetation in the study area is dominated by halophile plants, such as Halocnemum strobilaceum and Suaeda mollis (Ayari et al., 2016a, b, 2017).

\subsection{Experimental design and sampling}

Field investigations were carried out throughout the year 2013. For each visit, a plot of $20 \mathrm{~m} \times 20$ $\mathrm{m}$ was randomly set and then it was subdivided into four equal quadrats of $10 \mathrm{~m} \times 10 \mathrm{~m}$. Indeed, for each month, a plot was placed at a distance of $\pm 2 \mathrm{~m}$ from the plot of the previous month (Fig. 2).

Specimens of $H$. reaumurii were collected manually every hour when they emerged from their burrows or during their surface activity from the sunrise to the sunset. One day in each month during 2013 was selected to conduct the visiting and sampling (a total of 12 visiting and sampling days). To optimize the measurement of hourly activity of this species, four investigators participated in the visiting and sampling (1 investigator per quadrat $(10 \mathrm{~m} \times 10 \mathrm{~m}))$. They were present in the site 1-2 h before the sunrise and left the field 2-3 h after the sunset (when the surface activity is completely canceled). 


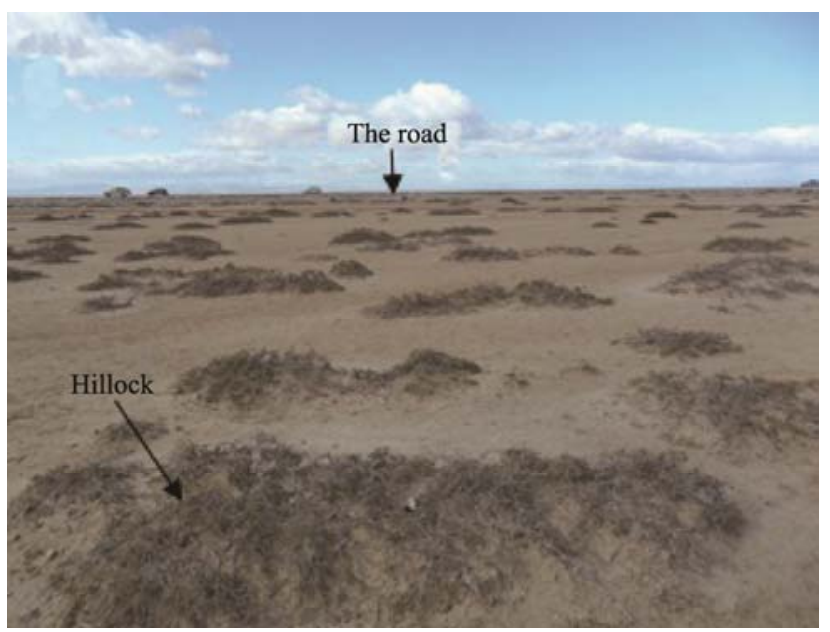

Fig. 1 Topography and geomorphology of the study site

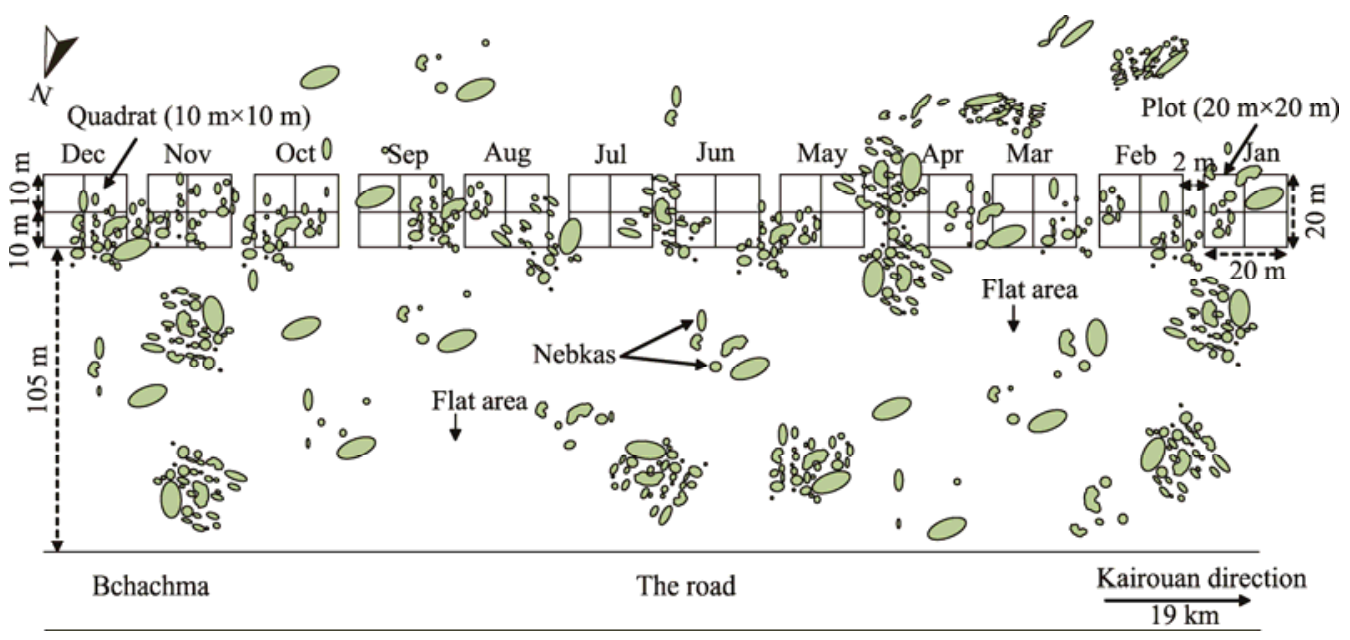

Fig. 2 Schematic diagram showing the experimental protocol adopted in this study. It should be noted that one plot was set in each month, with a total of 12 plots.

\subsection{Laboratory analysis and calculation of surface activity}

$H$. reaumurii individuals collected during each hour were put in perspex boxes, on which we labeled the hourly time interval in which the individuals were collected. Then, the boxes were transported to the laboratory. In the laboratory, the collected active individuals were sexed and measured using a Leica MS5 stereo-microscope with a micrometer (Leica Microsystems, Wetzlar, Germany). The monthly measurement of the locomotor activity intensity was based on the number of active individuals during each time interval on the studied days.

The photophase corresponds to the strictly enlightened period from the sunrise to the sunset. We calculated the percentage of the photophase exploitation by counting the hours of surface activity which occurred strictly during the enlightened period. Specifically, we firstly calculated the photophase duration during the enlightened period from the sunrise to the sunset on each studied day (expressed as $T p$ ), and converted the unit of $\mathrm{h}$ to the unit of min. For example, on 21 May 2013, the photophase duration during the enlightened period from the sunrise to the sunset was 14 h $20 \mathrm{~min}(19: 27-05: 07$ (LST)), corresponding to $860 \mathrm{~min}$ (Table 1). Then, we counted the hours that individuals of $H$. reaumurii were active during the enlightened period from the sunrise to the sunset on the studied day (expressed as $T a$ ), and also converted the unit of h to the unit of $\mathrm{min}$. Then, the percentage of the photophase exploitation was calculated as: $(T p / T a) \times 100 \%$. 
The Kairouan hourly temperatures of each studied day were taken from the website of http://french.wunderground.com/, and the daily mean temperatures are shown in Table 1.

Table 1 Photophase duration and daily mean temperature on the studied days in 2013

\begin{tabular}{|c|c|c|c|c|c|c|c|c|c|c|c|c|}
\hline & 30 Jan & $25 \mathrm{Feb}$ & $25 \mathrm{Mar}$ & $24 \mathrm{Apr}$ & 21 May & 28 Jun & $27 \mathrm{Jul}$ & 31 Aug & 30 Sep & 31 Oct & 20 Nov & $31 \mathrm{Dec}$ \\
\hline Sun & $07: 22$ & 07:01 & $06: 16$ & $05: 34$ & 05:07 & 05:02 & $05:$ & 48 & $06: 14$ & $06: 42$ & 07:00 & 07:29 \\
\hline $\mathrm{Su}$ & $17: 4$ & 7 & 7 & 19 & 27 & 7 & 1 & $18: 51$ & 06 & $7: 25$ & $17: 10$ & $17: 16$ \\
\hline $\begin{array}{l}\text { Photophase duration } \\
\text { (min) }\end{array}$ & 622 & 666 & 741 & 809 & 860 & 865 & 851 & 783 & 788 & 643 & 610 & 585 \\
\hline $\begin{array}{l}\text { Mean temperature } \\
\left({ }^{\circ} \mathrm{C}\right)\end{array}$ & $\begin{array}{l}12.5 \\
( \pm 2.5)\end{array}$ & $\begin{array}{c}13.3 \\
( \pm 2.4)\end{array}$ & $\begin{array}{c}17.8 \\
( \pm 2.9)\end{array}$ & $\begin{array}{c}17.1 \\
( \pm 0.8)\end{array}$ & $\begin{array}{c}22.9 \\
( \pm 3.8)\end{array}$ & $\begin{array}{c}25.7 \\
( \pm 4.6)\end{array}$ & $\begin{array}{c}32.9 \\
( \pm 6.4)\end{array}$ & $\begin{array}{c}25.5 \\
( \pm 2.5)\end{array}$ & $\begin{array}{c}27.9 \\
( \pm 3.7)\end{array}$ & $\begin{array}{c}20.4 \\
( \pm 3.0)\end{array}$ & $\begin{array}{c}17.1 \\
( \pm 4.2)\end{array}$ & $\begin{array}{c}13.2 \\
( \pm 2.9)\end{array}$ \\
\hline
\end{tabular}

Note: Values in the brackets are the standard deviations. It should be noted that the photophase duration was calculated as the sunset time minus the sunrise time, and the unit of $\mathrm{h}$ was converted to the unit of min.

\subsection{Statistical analysis}

We used the general linear model (GLM) to test whether the number of active individuals (males and females) presented an hourly variation and/or a monthly variation. GLM was also used to test the effect of temperature on the surface activity of $H$. reaumurii individuals. Moreover, we applied the $\chi^{2}$ test to compare the different percentages of photophase exploitation and to test the effect of temperature on the surface activity of $H$. reaumurii individuals.

The one way ANOVA was performed to model the monthly variation in the body size of active $H$. reaumurii individual. Statistical analyses were performed with R 3.4.2 for Windows, SPSS 21.0 and SigmaPlot 11.0.

\section{Results}

\subsection{Effect of temperature on the surface activity}

As shown in Figure 3, temperature exhibited a significant quadratic effect $(Z=25.19, P<0.000)$ on the number of active $H$. reaumurii individuals. The number of active individuals increased when the temperature ranged between $13^{\circ} \mathrm{C}$ and $29^{\circ} \mathrm{C}$. However, it decreased when the temperature fell to $10^{\circ} \mathrm{C}$ or rose to $40^{\circ} \mathrm{C}$.

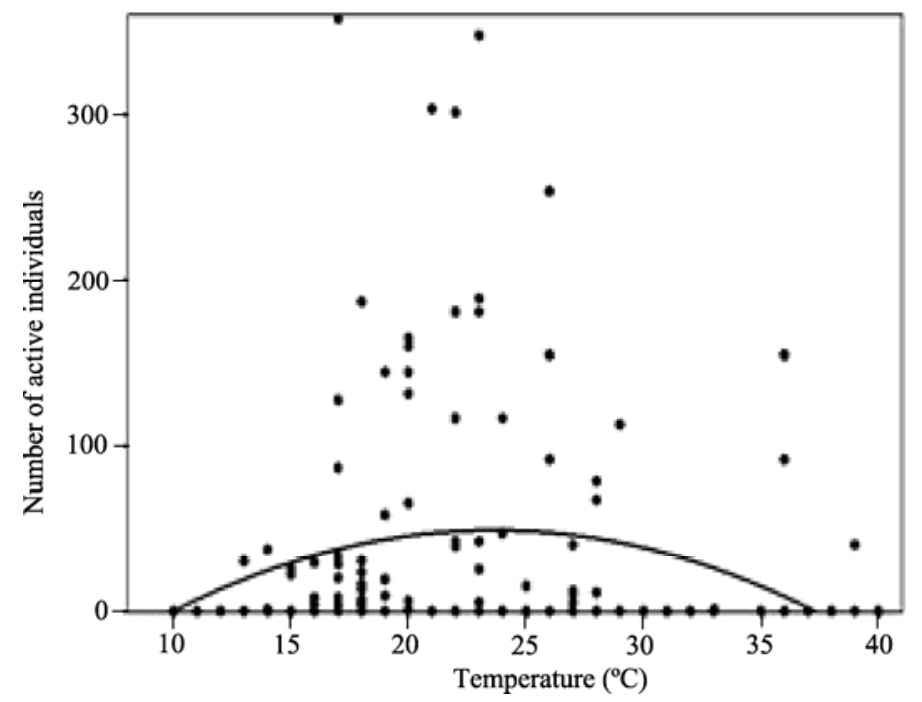

Fig. 3 Effect of temperature on the surface activity of Hemilepistus reaumurii individuals

\subsection{Monthly and hourly variations of the surface activity}

Generally, a significant monthly variation of active $H$. reaumurii individuals was observed $(Z=90.45, P<0.000$; Fig. 4a). Indeed, $H$. reaumurii individuals were mostly active in March 
$(Z=15.17, P<0.001)$ and October $(Z=5.86, P<0.001)$. Specifically, males were mostly active in $\operatorname{March}(Z=13.07, P<0.001)$, September $(Z=3.87, P=0.000)$ and October $(Z=4.89, P=0.000)$, while females were mostly active in March $(Z=8.09, P=0.000)$ and June $(Z=5.72, P=0.000)$.

Our results showed a significant hourly variation in the surface activity of active $H$. reaumurii individuals $(Z=23.86, P<0.001$; Fig. $4 \mathrm{~b})$. Both males and females were statistically active during 06:00-07:00 ( $Z=20.20, P<0.0001), 07: 00-08: 00 \quad(Z=23.08, P<0.0001), 14: 00-15: 00 \quad(Z=10.75$, $P<0.001), 15: 00-16: 00(Z=10.17, P<0.001), 18: 00-19: 00(Z=9.37, P<0.001)$ and 19:00-20:00 $(Z=17.11, P<0.0001)$.
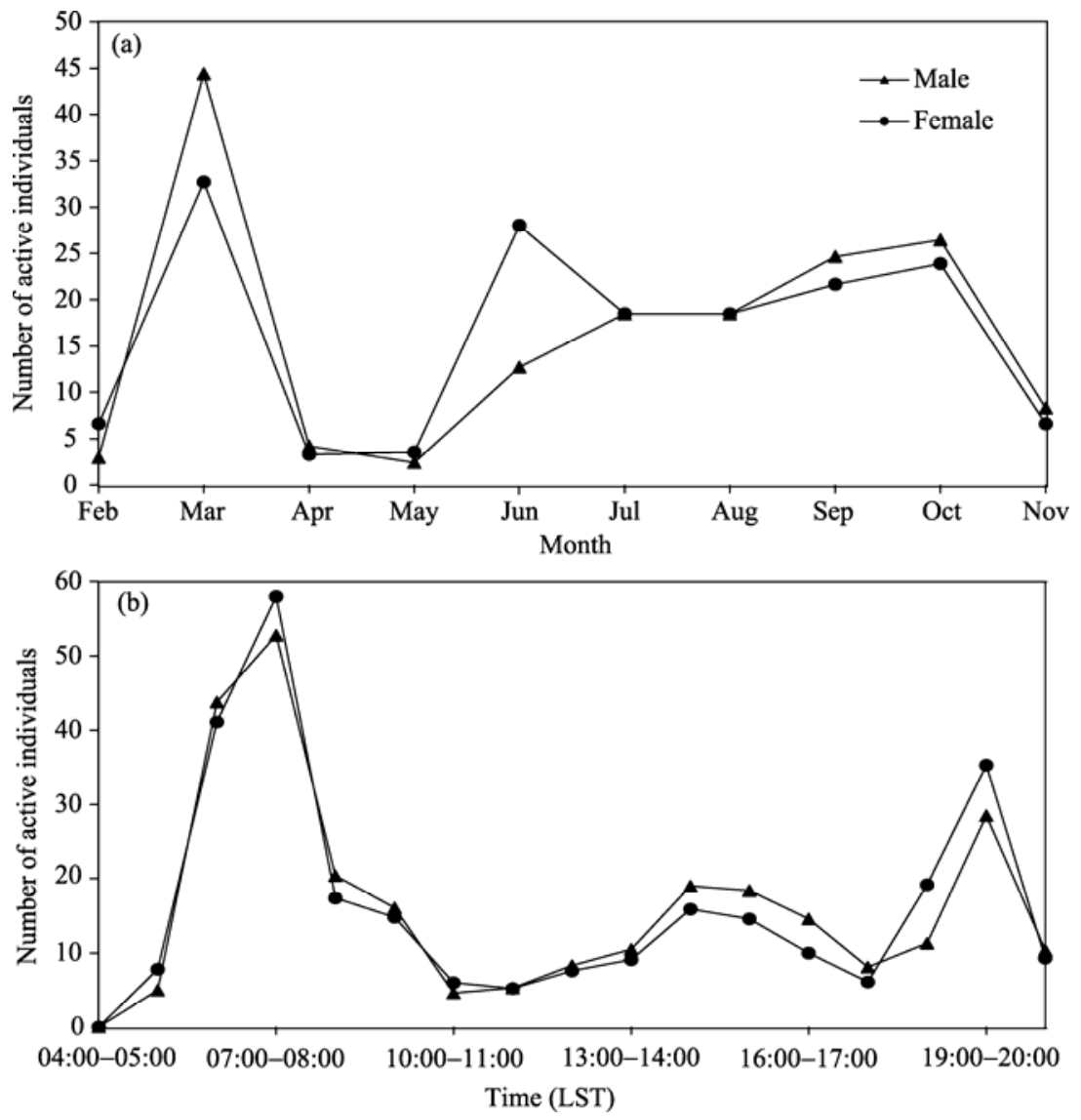

Fig. 4 Monthly (a) and hourly (b) variations in the number of active H. reaumurii individuals

\subsection{Plasticity of the surface activity}

In this study, a highly significant monthly variation in the photophase exploitation of the surface activity of active $H$. reaumurii individuals was highlighted $\left(\chi^{2}=16.87, P<0.0001\right)$. In fact, the photophase was well exploited in March, April and November and poorly exploited during June and July (Table 2).

Table 2 Monthly variation in the activity pattern of $H$. reaumurii individuals

\begin{tabular}{|c|c|c|c|c|c|c|c|c|c|c|c|c|}
\hline & Jan & Feb & Mar & Apr & May & Jun & Jul & Aug & Sep & Oct & Nov & Dec \\
\hline $\begin{array}{c}\text { Percentage of } \\
\text { photophase } \\
\text { exploitation } \\
(\%)\end{array}$ & - & 54.0 & 81.0 & 81.5 & 49.0 & 41.6 & 42.3 & 54.0 & 46.0 & 52.0 & 69.0 & - \\
\hline Life cycle & Quiescence & Emergence & \multicolumn{4}{|c|}{$\begin{array}{l}\text { Pairs formation and } \\
\text { reproduction }\end{array}$} & \multicolumn{5}{|c|}{ Growth } & Quiescence \\
\hline
\end{tabular}

Note: -, no data.

Results showed that the surface activity pattern of $H$. reaumurii individuals varied considerably 
over the year (Fig. 5). Surface activity was observed in 10 months, i.e., from February to November. $H$. reaumurii individuals were inactive in January and December. Furthermore, the majority of the surface activity peak occurred during the daytime (diurnal behaviour). A seasonal shift in the surface activity pattern was also observed, ranging from a unimodal pattern (February and November) to a clear bimodal one (from May to October), passing through an intermediate pattern (March and April; Fig. 5).

Specifically, during February and November, the surface activity profiles of active $H$. reaumurii individuals showed a unimodal pattern with one peak occurring in the middle of the day. From May to October, results showed a shift of surface activity in the afternoon. That is, a bimodal activity pattern occurring around the light-dark transition (sunrise and sunset) was observed during these months (Fig. 5). This sensitivity to dawn and dusk was statistically significant $(Z=16.96, P<0.0001)$.

Comparisons of surface activity between sexes revealed that males were significantly more active than females during March, September, and November (Table 3). Furthermore, the most important surface activity was observed in females during February, May, June, and October. Result showed also that males were more active than females during the time intervals 12:00-13:00 $(Z=3.21, P=0.000)$ and 17:00-18:00 $(Z=3.07, P=0.000)$.

Table 3 Statistical characteristics of the active $H$. reaumurii individuals at the monthly scale

\begin{tabular}{|c|c|c|c|c|c|c|c|c|}
\hline \multirow{2}{*}{ Month } & \multicolumn{2}{|c|}{ Number } & \multicolumn{2}{|c|}{ Percentage (\%) } & \multirow{2}{*}{ Khi-2 test } & \multicolumn{2}{|c|}{ Size $(\mathrm{mm})$} & \multirow{2}{*}{ ANOVA test } \\
\hline & Male & Female & Male & Female & & Male & Female & \\
\hline Jan & - & - & - & - & - & - & - & - \\
\hline Feb & 50 & 112 & 31 & 69 & $P=0.0001$ & $21.9 \pm 1.5$ & $21.4 \pm 1.3$ & $P=0.018$ \\
\hline Mar & 755 & 556 & 57 & 43 & $P=0.0001$ & $20.0 \pm 1.5$ & $19.1 \pm 1.3$ & $P<0.0001$ \\
\hline Apr & 71 & 56 & 56 & 44 & NS & $19.7 \pm 1.5$ & $18.8 \pm 1.3$ & $P<0.0001$ \\
\hline May & 41 & 60 & 40 & 60 & $P=0.008$ & $19.1 \pm 1.5$ & $18.9 \pm 1.5$ & NS \\
\hline Jun & 216 & 476 & 31 & 69 & $P<0.0001$ & $13.0 \pm 3.3$ & $11.9 \pm 3.6$ & $P<0.0001$ \\
\hline Jul & 314 & 314 & 50 & 50 & NS & $15.8 \pm 1.9$ & $14.4 \pm 2.0$ & $P<0.0001$ \\
\hline Aug & 625 & 590 & 51 & 49 & NS & $20.2 \pm 2.1$ & $19.5 \pm 2.0$ & $P<0.0001$ \\
\hline Sep & 419 & 368 & 54 & 46 & $P=0.010$ & $21.7 \pm 1.4$ & $20.6 \pm 1.4$ & $P<0.0001$ \\
\hline Oct & 406 & 450 & 49 & 51 & $P=0.033$ & $22.5 \pm 1.4$ & $21.7 \pm 1.4$ & $P<0.0001$ \\
\hline Nov & 141 & 112 & 55 & 45 & $P<0.0001$ & $22.4 \pm 1.5$ & $21.6 \pm 1.5$ & $P<0.0001$ \\
\hline Dec & - & - & - & - & - & - & - & - \\
\hline
\end{tabular}

\subsection{Monthly variation in the body size of active $H$. reaumurii individuals}

The body size of active $H$. reaumurii individuals varied significantly between months $(H=3675.68$, $P<0.001)$. It decreased from February to June, and increased from July, reaching to the maximal in October and November (Table 3; Fig. 6). The body size of active $H$. reaumurii individuals also varied significantly between sexes. Active males had a larger body size than active females during almost all the activity months (February to November) except for May (Table 3). During this month (May), no difference in body size between active males and females was observed.

\section{Discussion}

\subsection{Effect of temperature on the surface activity}

Temperature seems to be a strong determinant of temporal activity patterns (e.g., dispersion, reproduction, foraging, etc.) of $H$. reaumurii individuals. The quadratic effect of temperature on the number of active $H$. reaumurii individuals revealed that no surface activity was observed below $10^{\circ} \mathrm{C}$ and over $40^{\circ} \mathrm{C}$. Temperatures of $10^{\circ} \mathrm{C}$ and $40^{\circ} \mathrm{C}$ could be regarded as the minimum and maximum of ambient temperatures that $H$. reaumurii individuals tolerate for their surface activity, respectively. Eduard and Linsenmair (1971) showed that individuals of $H$. reaumurii died 

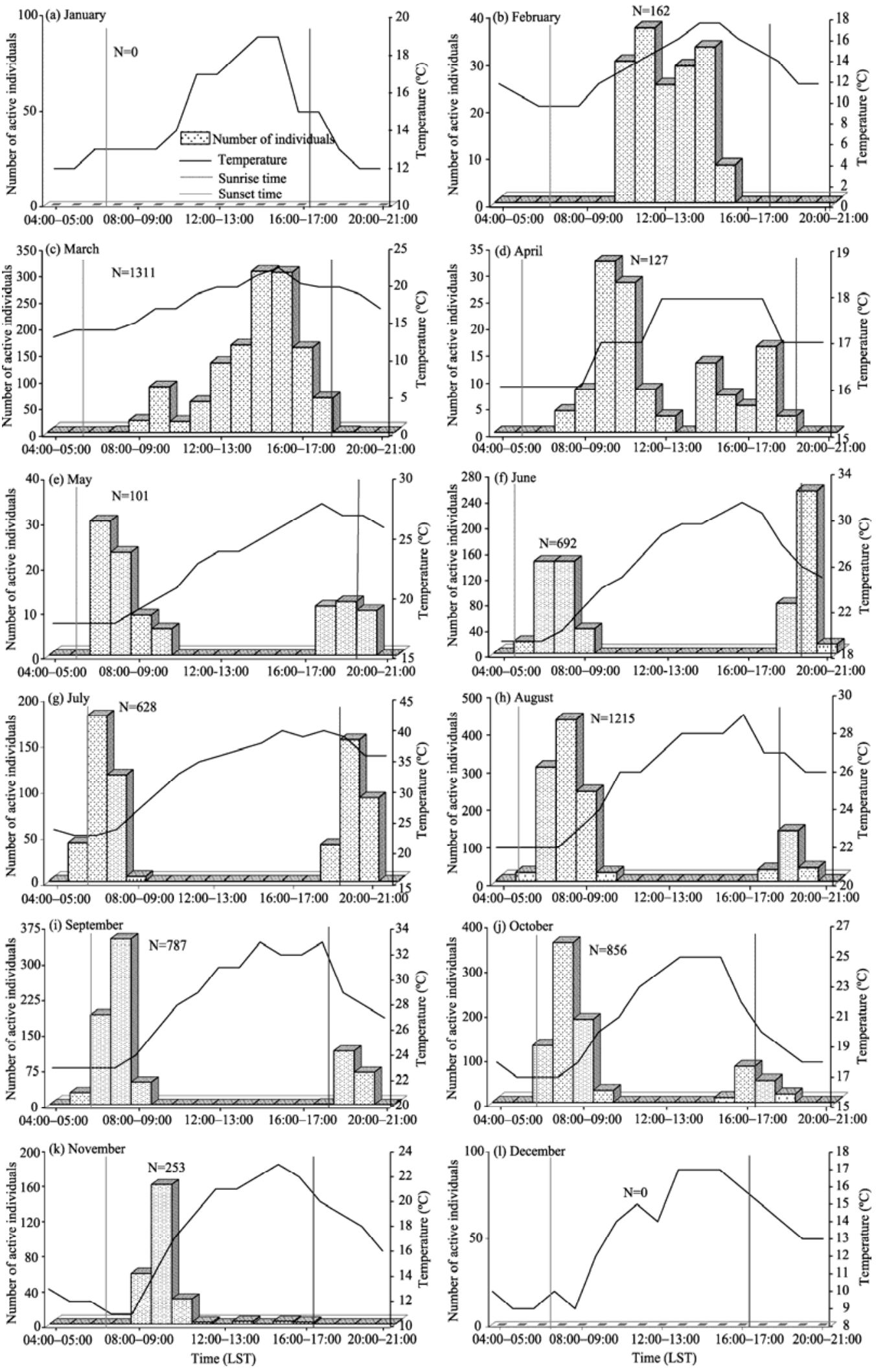

Fig. 5 Plasticity of the surface activity of the active H. reaumurii individuals. "N" means the total number of active individuals in each month. $H$. reaumurii individuals were inactive in January and December. 


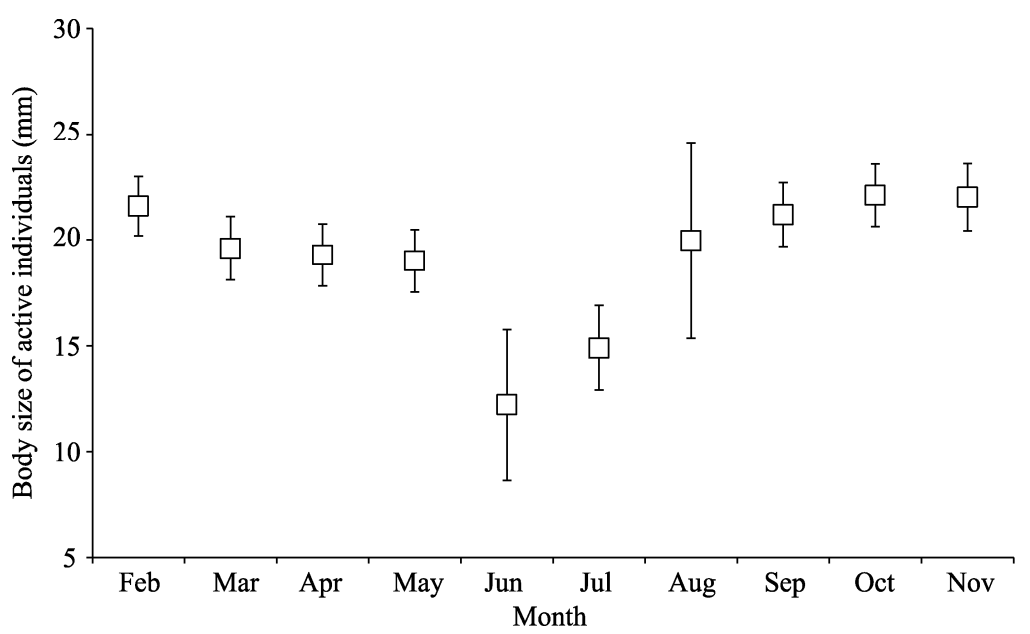

Fig. 6 Monthly variation in the body size of active $H$. reaumurii individuals from February to November. The "whiskers" above and below the box display the locations of the maximum and minimum values, respectively.

within 15-30 min when they were exposed to a temperature of $50^{\circ} \mathrm{C}-60^{\circ} \mathrm{C}$. Like several diurnal ants (Cros et al., 1997; Pol and de Casenave, 2004; Jayatilaka et al., 2011), H. reaumurii exhibited a wide flexibility of activity pattern by adjusting the length of the active period, almost completely restricted in daytime, especially in the specific time of the day to avoid critical temperatures (low and high temperatures) according to season. This can explain that during December and January, in which temperature fell below a certain threshold $\left(6^{\circ} \mathrm{C}-17^{\circ} \mathrm{C}\right.$ and $7^{\circ} \mathrm{C}-18^{\circ} \mathrm{C}$, respectively), individuals of $H$. reaumurii completely stop their surface activity to avoid desiccation and remain into their burrows. The start of quiescence observed during these two months would be considered as an adaptation to avoid the cold winter temperatures. Furthermore, the highest number of active $H$. reaumurii individuals over the year was concentrated at temperatures of $13^{\circ} \mathrm{C}-29^{\circ} \mathrm{C}$, which suggests that these temperature values represent the optimal limits of air temperature for the surface activity of $H$. reaumurii individuals. Our findings are in agreement with those of Nasri et al. (1996), who demonstrated experimentally that individuals of $H$. reaumurii exposed to a long photoperiod (15-h light/9-h dark) could stop their growth and reproduction at $15^{\circ} \mathrm{C}$. The present results of the photophase exploitation over the year may confirm the effect of temperature on the surface activity of $H$. reaumurii individuals. Our results show that photophase is more exploited in March, April, and November than in the other months. During these three months (March, April and November), the recorded temperatures ranged between $15^{\circ} \mathrm{C}$ and $23^{\circ} \mathrm{C}$, which represent the favourable temperatures for the maximum exploitation of photophase. Furthermore, the photophase is less exploited during June and July in which the recorded temperatures were the highest. Thus, our first hypothesis that $H$. reaumurii would reduce its surface locomotor activity during the warmest months while increase its daily period of surface activity during the months with suitable temperatures is verified.

\subsection{Monthly and hourly variations of the surface activity}

Monthly variation in the surface activity of $H$. reaumurii individuals between sexes revealed that both males and females were more active in March. In fact, March represented the dispersal period (Shachak and Yair, 1984; Nasri et al., 1996; Ayari et al., 2016b), during which males and females leave their families and disperse in order to find a new burrow and a partner. This crucial period of life cycle could explain the high intensity of surface activity during this month. In June (the specific month for the activity of females, coinciding with the end of the reproductive period), we noticed a larger number of females on the surface compared to males, probably because females had to compensate for metabolism losses during reproduction by increasing their foraging activity. During this period, most of the males remained in their burrows and took care of their offspring (Shachak, 1980; Linsenmair, 1984; Baker, 2005). Males were specifically more active in 
September and October than the other months. These two months (September and October) corresponded to the last phase of the juvenile growth period which precedes the quiescence. During this period, $H$. reaumurii individuals try to accumulate the maximum of nutritive matter to pass winter in a quiescence state.

In this study, hourly variation analysis on the surface activity of $H$. reaumurii individuals revealed that both males and females were more active during 06:00-08:00 and 19:00-20:00, coinciding with sunrise and sunset, respectively. The anticipation and delaying relative to sunrise and sunset allowed $H$. reaumurii individuals to maintain a minimum of 6-h activity during the high temperature months that could reach up to $45^{\circ} \mathrm{C}$ in the middle of the day. Under this high temperature, $H$. reaumurii individuals were forced to be active after the sunset and before the sunrise, exposing them to their main predator, Scorpio maurus, which exhibits a nocturnal surface activity (Dubinsky et al., 1979). The restriction of surface activity around sunrise and sunset during hot months was observed in the dune beetle Erodius sauditus (Robinson and Clayton, 2001) and in the Sahara scorpion Androctonus australis when the daily temperature differences on the sand surface might exceed $60^{\circ} \mathrm{C}$ (Fleissner and Fleissner, 1998).

The onset of the surface activity of $H$. reaumurii seemed to be triggered by sunrise. Ashoff (1986) highlighted that for day-active animals, the beginning of surface activity was phased with the dawn. According to Fleissner and Fleissner (2002), various organisms may recognize a certain moment during dawn and follow this signal as an individually defined set point throughout changing seasonal conditions. Cloudsley-Thompson (1991) indicated that the decision to be active or not results from various cues available to the organisms after they are aroused by their circadian clock. Unlike other various desert arthropods (Cloudsley-Thompson, 1991; Alpato et al., 1994), the locomotor behaviour of $H$. reaumurii under controlled environmental conditions received little attention (Nasri-Ammar and Morgan, 2005; Ayari et al., 2017). Nasri-Ammar and Morgan (2005) and Ayari et al. (2017) studied the locomotor rhythm of pairs of $H$. reaumurii in the laboratory, and showed that this species exhibited a diurnal locomotor activity with two activity peaks, which occurred respectively around sunrise and sunset. They also demonstrated that the locomotor rhythm of $H$. reaumurii was controlled by an endogenous circadian clock with period approximately closing to $24 \mathrm{~h}$. Similar to other desert species such as the tenebrionid beetles Trigonoscelis gigas (Alpato et al., 1994; Alpatov et al., 1999; Zotov and Alpatov, 2004) and other insect species (Lewis et al., 1991), the circadian clock of $H$. reaumurii probably involved two oscillators. Exactly, one oscillator is synchronized with sunrise and the other one is synchronized with sunset. The crepuscular locomotor activity rhythm of $H$. reaumurii clearly had an adaptive value in restricting its surface activity to coincide with optimal environmental conditions of light, temperature and relative humidity (Nasri-Ammar and Morgan, 2005).

Our results also revealed a seasonal shift in the activity pattern, from a unimodal pattern to a bimodal pattern. Natal dispersion, for considerable distances (Ayari et al., 2016b), started in mid-February with only one low activity peak (unimodal pattern). In March and April, $H$. reaumurii had a $10-11 \mathrm{~h}$ of surface activity with several types, including foraging, searching, digging, maintaining and defending burrows, monogamous pair formation, etc. During these months (March and April), surface activity of $H$. reaumurii individuals began at 07:00 and continued at 19:00. From May to October, two activity peaks were revealed (bimodal pattern) and surface activity was shifted towards sunset and sunrise.

\subsection{Monthly variation in the body size of active $H$. reaumurii individuals}

The monthly variation in the body size of active individuals could be explained by the decortication of the life cycle of $H$. reaumurii at the study site. The dispersal phase started at the end of February and was followed by the pair formation period occurring from the end of March until April. The reproduction period that began in May was characterized by the presence of the reproductive females. These females realized only one brood per life cycle (Ayari et al., 2016b). Therefore, a lot of energy was spent during March-May which may explain the gradual decrease of the body size of active $H$. reaumurii individuals. In June and July, a difference in body size between adults and juveniles was clearly observed (Ayari, unpublished data). During these two 
months, the body length of the majority of active $H$. reaumurii individuals did not exceed $15 \mathrm{~mm}$. Adults did not exploit the temporal niches differently from juveniles and they just limited their surface activity during this period. Kennedy et al. (2000) studied the locomotor activity of the amphipod Orchestia tuberculata, and proved the existence of a significant negative influence on the survival of juveniles in the presence of adults by intraspecific predation. For the talitrid Orchestia gammarellus, Ayari et al. (2015) mentioned the most important activity and stability of the locomotor rhythm for juveniles. The two months of June and July could be considered as the active period of the offspring for $H$. reaumurii. From August to November, the body size of juveniles increased whereas a high percentage of mortality of adults was noted (Ayari et al., 2016b). To sum up, our third hypothesis that the body size of active individuals would change with months is verified.

The body sizes of males were larger than that of females. The difference in body size highlighted in the present study would suggest the development of a sexual size dimorphism (SSD). This result is contradictory with the finding of Vandel (1949), who mentioned that there is no sexual dimorphism of size and color in $H$. reaumurii. The natural selection of large-size males could be an explanation of our result. In fact, SSD resulted from sexually antagonistic selection favouring different optimal body sizes for both genders. The evolution of independent size optima is constrained by genetic correlations between sexes, as well as the physiological, developmental and phylogenetic constraints (Blanckenhorn, 2007; Fairbairn, 2007). Smith and Brockmann (2014) pointed out that mate competition between males can contribute to the evolution of males with larger body size.

\section{Conclusions}

The present study found that temperature has a quadratic effect on the number of active $H$. reaumurii individuals. Indeed, individuals of $H$. reaumurii completely stopped their surface activity during the coldest months and limited their surface activity to periods with suitable temperatures during the warmest months. Individuals of this species increased their daily period of surface activity during months with mild temperature. During the warmest months, $H$. reaumurii shifted its activity time around sunrise and sunset to avoid the extreme heat which occurred in the middle of the day. This flexibility of the surface activity could represent an adaptive strategy adopted by this species to survive in arid environments.

To better understand the surface locomotor behaviour of $H$. reaumurii individuals as an adaptive strategy to survive in arid environments, it would be interesting to study the seasonal variation of the surface locomotor activity in the laboratory. A comparison between results obtained in the laboratory and in the filed would be also interesting. Furthermore, it would be interesting to compare the surface locomotor activity between adults and juveniles of the same species in the field and in the laboratory.

\section{Acknowledgements}

This work was supported by the University of Tunis El Manar. We wish to thank Mrs. Sabiha KHIARI-AYARI, Ms. Nada AYARI, and Mr. Assad ABIDI for their important contribution in accomplishing the field work of this study. We also wish to thank Dr. Julian REYNOLDS for constructive remarks and English revision of the manuscript. We also thank the two anonymous reviewers for their helpful comments on this paper.

\section{References}

Alpato A M, Rietveld W J, Oryntaeva L B, et al. 1994. Properties of the two-peak free running circadian rhythm of locomotor activity of the sand desert beetle Trigonoscelis gigas reitt. Biological Rhythm Research, 25(2): 153-167.

Alpatov A M, Zotov V A, Tshernyshev W B, et al. 1999. Endogenous circadian rhythm is a crucial tool for survival of the sand-desert tenebrionid beetle Trigonoscelis gigas Reitter. Biological Rhythm Research, 30(1): 104-109.

Aschoff J. 1986. Anticipation of daily meal: a process of learning due to entrainment. Monitore Zoologico Italiano, 20: $195-219$. 
Ayari A, Jelassi R, Ghemari C, et al. 2015. Effect of age, sex, and mutual interaction on the locomotor behavior of Orchestia gammarellus in the supralittoral zone of Ghar El Melh lagoon (Bizerte, Tunisia). Biological Rhythm Research, 46(5): 703-714.

Ayari A, Raimond M, Souty-Grosset C, et al. 2016a. Hierarchical organization of the cuticle of the subsocial desert isopod, Hemilepistus reaumurii. Journal of Structural Biology, 193(2): 115-123.

Ayari A, Richard F J, Souty-Grosset C, et al. 2016b. Family identity of the sub-social desert terrestrial isopod Hemilepistus reaumurii. Journal of Arid Environments, 134: 10-16.

Ayari A, Jelassi R, Ghemari C, et al. 2017. Locomotor activity pattern in pairs of the subsocial desert isopod Hemilepistus reaumurii. Biological Rhythm Research, 48(3): 449-457.

Baker M B. 2005. Experience influences settling behaviour in desert isopods, Hemilepistus reaumuri. Animal Behaviour, 69(5): 1131-1138.

Blanckenhorn W U. 2007. Case studies of the differential-equilibrium hypothesis of sexual size dimorphism in two dung fly species. In: Fairbairn D J, Blanckenhorn W U, Szekély T. Sex, Size and Gender Roles: Evolutionary Studies of Sexual Size Dimorphism. Oxford, UK: Oxford University Press, 106-114.

Bohli D, Morgan E, Charfi-Cheikhrouha F, et al. 2006. Study of locomotor activity of Talitrus saltator (Crustacea, Amphipoda) from Zouarâa beach (Tunisia). In: Scapini F. Proceedings of the MEDCORE International Conference, $10^{\text {th }}-14^{\text {th }}$ November 2005. Florence: Firenze University Press, 209-219. (in Italian)

Bohli-Abderrazak D, Ayari A, Morgan E, et al. 2012. Towards a characterization of the locomotor activity rhythm of the supralittoral isopod Tylos europaeus. Chronobiology International, 29(2): 166-174.

Chelazzi L, Colombini I. 1989. Zonation and activity patterns of two species of the genus Phaleria Latreille (Coleoptera Tenebrionidae) inhabiting an equatorial and a Mediterranean sandy beach. Ethology Ecology \& Evolution, 1(4): 313-321.

Cloudsley-Thompson J L. 1990. Thermal ecology and behaviour of Physadesmia globosa (Coleoptera: Tenebrionidae) in the Namib desert. Journal of Arid Environments, 19(3): 317-324.

Cloudsley-Thompson J L. 1991. Ecophysiology of Desert Arthropods and Reptiles. Heidelberg, Berlin, Tokyo: Springer-Verlag, 203.

Cloudsley-Thompson J L. 2001. Thermal and water relations of desert beetles. Naturwissenschaften, 88(11): 447-460.

Cros S, Cerdá X, Retana J. 1997. Spatial and temporal variations in the activity patterns of Mediterranean ant communities. Écoscience, 4(3): 269-278.

Dubinsky Z, Steinberger Y, Shachak M. 1979. The survival of the desert isopod Hemilepistus reaumurii (Audouin) in relation to temperature (Isopoda, Oniscoidea). Crustaceana, 36(2): 147-154.

Eduard K, Linsenmair C. 1971. Pairing and couple cohesion in the monogamous desert isopod Hemilepistus reaumuri (Crustacea, Isopoda, Oniscoidea). Journal of Animal Psychology, 29(2): 134-155.

Fairbairn D J. 2007. Introduction: the enigma of sexual size dimorphism. In: Fairbairn D J, Blanckenhorn W U, Szekély T. Sex, Size and Gender Roles: Evolutionary Studies of Sexual Size Dimorphism. Oxford, UK: Oxford University Press, 1-10.

Fleissner G, Fleissner G. 1998. Natural photic zeitgeber signals and underlying neuronal mechanisms in Scorpions. In: Touitou Y. Biological Clocks: Mechanisms and Applications. Paris: Elsevier, 171-180.

Fleissner G, Fleissner G. 2002. Perception of natural zeitgeber signals. In: Kumar V. Biological Rhythms. New Delhi, New York: Narosa/Springer, 71-82.

Jayatilaka P, Narendra A, Reid S F, et al. 2011. Different effects of temperature on foraging activity schedules in sympatric Myrmecia ants. Journal of Experimental Biology, 214(16): 2730-2738.

Jelassi R, Ayari A, Nasri-Ammar K. 2013. Seasonal variation of locomotor activity rhythm of Orchestia gammarellus in the supralittoral zone of Ghar Melh lagoon (North-East of Tunisia). Biological Rhythm Research, 44(6): 956-967.

Kennedy F, Naylor E, Jaramillo E. 2000. Ontogenetic differences in the circadian locomotor activity rhythm of the talitrid amphipod crustacean Orchestoidea tuberculata. Marine Biology, 137(3): 511-517.

Lewis R D, Bullivant A G, King V M. 1991. A dual pacemaker model for the circadian system of the insect Hemideina thoracica. Journal of Interdisciplinary Cycle Research, 22(4): 293-309.

Linsenmair K E. 1984. Comparative studies on the social behavior of the desert isopod Hemilepistus reaumuri and of a Porcellio species. In: Sutton S L, Holdich D M. The Biology of Terrestrial Isopods. Oxford: Oxford University Press, 53: 423-454.

Linsenmair K E. 2007. Sociobiology of terrestrial isopods. In: Duffy J E, Thiel M. Evolutionary Ecology of Social and Sexual Systems: Crustaceans as Model Organisms. New York: Oxford University Press, 339-364.

Nasri K, Juchault P, Mocquard J P, et al. 1996. Seasonal reproduction in Hemilepistus reaumuri (Audouin, 1826), terrestrial isopod of semi-arid zones. Crustaceana, 69(2): 223-235. 
Nasri-Ammar K, Morgan E. 2005. Preliminary observations on the natural variation in the endogenous rhythm of the desert isopod Hemilepistus reaumurii. European Journal of Soil Biology, 41(3-4): 63-68.

Nasri-Ammar K, Jelassi R, Ayari A, et al. 2016. Seasonal changes of locomotor activity patterns in the desert isopod Hemilepistus reaumuri. Biological Rhythm Research, 47(1): 25-38.

Parmenter R R, Parmenter C A, Cheney C D. 1989. Factors influencing microhabitat partitioning in arid-land darkling beetles (Tenebrionidae): temperature and water conservation. Journal of Arid Environments, 17(1): 57-67.

Pol R, de Casenave J L. 2004. Activity patterns of harvester ants Pogonomyrmex pronotalis and Pogonomyrmex rastratus in the central Monte desert, Argentina. Journal of Insect Behavior, 17(5): 647-661.

Robinson M D, Clayton D A. 2001. Thermal ecology and seasonal activity patterns of Erodius sauditus, an Arabian dune beetle (Tenebrionidae: Erodinae). In: Prakash I. Ecology of Desert Environments. Jodhpur: Scientific Publishers, 281-291.

Shachak M. 1980. Energy allocation and life history strategy of the desert isopod H. reaumuri. Oecologia, 45(3): 404-413.

Shachak M, Yair A. 1984. Population dynamics and the role of Hemilepistus reaumuri in a desert ecosystem. In: Sutton S L, Holdich D M. The Biology of Terrestrial Isopods. Oxford: Oxford University Press, 53: 295-314.

Smith M D, Brockmann H J. 2014. The evolution and maintenance of sexual size dimorphism in horseshoe crabs: an evaluation of six functional hypotheses. Animal Behaviour, 96: 127-139.

Vandel A. 1949. On a collection of terrestrial isopods collected by F. PIERRE, in southern Algeria, and on the presence of a new Irano-Turanian element in the Saharan fauna. Bulletin of the Zoological Society of France, 74: 310-316.

Zotov V A, Alpatov A A. 2004. Ecological aspects of circadian rhythms in six species of omni-seasonal beetles (Coleoptera, Tenebrionidae) inhabiting Kara Kum Desert (Turkmenistan). Biological Rhythm Research, 35(1-2): 93-103. 